\title{
Conservative management of esophageal perforation caused by misplacement of endotracheal tube
}

\author{
Reza Rezaei ${ }^{1}$, Yousef Yousefi ${ }^{2}$ \\ ${ }^{1}$ Endoscopic and Minimally Invasive Surgery Research Center, Mashhad University of Medical Sciences, \\ Mashhad, Iran \\ ${ }^{2}$ Lung Diseases Research Center, Mashhad University of Medical Sciences, Mashhad, Iran
}

Kardiochirurgia i Torakochirurgia Polska 2019; 16 (2): 100-102

Esophageal perforation remains a potentially fatal disease with mortality rates of $10 \%$ to $40 \%$ [1, 2]. Today it is accepted that the method for the treatment of esophageal perforation plays an important role in the mortality rate. There are also several reports of non-operative treatments, by stopping all oral intake and providing intravenous nutrition or using a covered stent in patients with small ruptures localized to the mediastinum [3].

We report a case of esophageal perforation caused by misplacement of the endotracheal tube. The diagnosis and management strategy are discussed here.

The patient is a 65-year-old woman candidate for coronary artery bypass grafting. During the induction of anesthesia, intubation of the patient was difficult and the tracheal tube was inadvertently placed in the esophagus. We

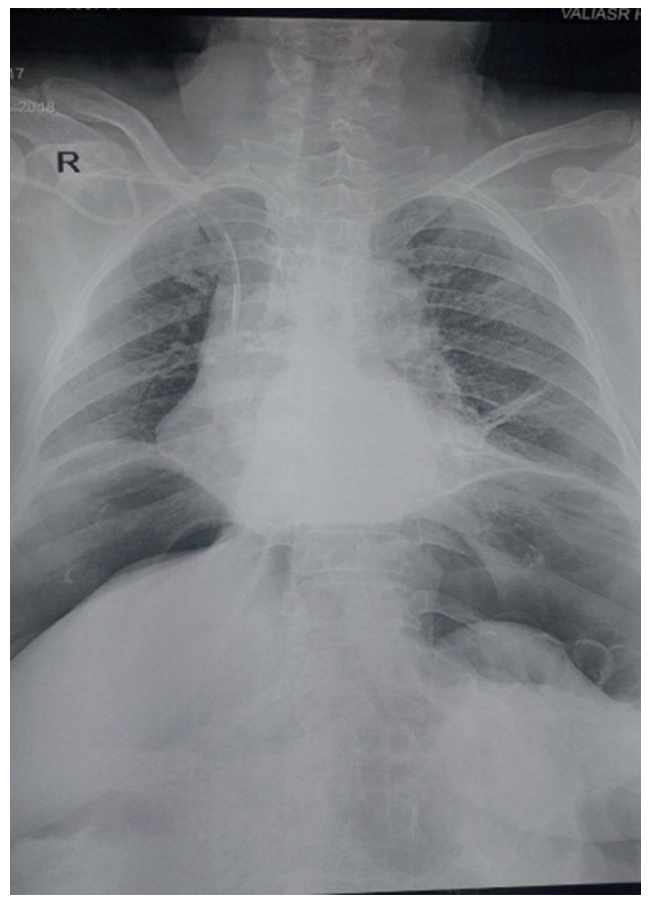

Fig. 1. $1^{\text {st }}$ postop. chest X-ray noticed the presence of blood secretions in the NG tube and decreased arterial oxygen saturation. The operation was halted by the order of the anesthetist. The patient was reversed and transferred to recovery for further investigation. She complained of central chest pain with radiation to her back. On examination, the chest breathing sounds were equal bilaterally and her vital signs were: pulse rate $98 / \mathrm{min}$, blood pressure (BP) $142 / 72 \mathrm{~mm} \mathrm{Hg}, \mathrm{SaO}_{2}=91 \%$ on air and temperature $37.5^{\circ} \mathrm{C}$.

Investigations including chest radiography, electrocardiography (ECG), full blood count, and biochemistry screen were performed. In radiography, free air under the diaphragm and widened mediastinum were observed (Fig. 1). Lab work showed white blood count cells count (WBC) $=11.1$, neutrophils $=78 \%$, and trigger point injection $(\mathrm{TPI})=20$.

In order to examine the air below the diaphragm, upper gastrointestinal Gastrografin contrast study was performed but no contrast leak was seen (Figs. 2, 3). Thoracic and abdominal computed tomography (CT) scan were performed to rule out other diagnoses, but they were normal except for bilateral pleural effusion (Fig. 4).

The patient was transferred to the coronary care unit (CCU) department. Because of good general condition and lack of esophageal contrast leak, a conservative approach was suggested for patient management. Nil per os (NPO) regimen and parenteral nutrition were selected. Antibiotic therapy with ceftriaxone $1 \mathrm{~g} / \mathrm{q} 12 \mathrm{~h}$, metronidazole $500 \mathrm{mg} / \mathrm{q} 8 \mathrm{~h}$, with pantoprazole $40 \mathrm{mg} / \mathrm{q} 12 \mathrm{~h}$, and anticoagulant therapy were started. Daily examinations were performed by physical examinations and vital signs and radiographs. The pain and tenderness of the abdomen decreased slightly and leukocytosis was resolved gradually. After a week, the patient's regimen began by mouth and progressed cautiously. On the $10^{\text {th }}$ day, the patient was placed under percutaneous coronary intervention $(\mathrm{PCl})$ and on the eleventh day she was discharged with a good general condition.

Esophageal perforation is a life-threatening clinical situation, diagnosis is difficult and scientific therapy experiences for this condition are lacking [4]. Esophageal per-

Address for correspondence: Yousef Yousefi, Lung Diseases Research Center, Mashhad University of Medical Sciences, Mashhad, Iran, phone: 05138012840, fax: 05138402972, e-mail: yousefiy961@mums.ac.ir

Received: 16.10.2018, accepted: 28.04.2019. 
foration caused by iatrogenic or other reasons has been reported frequently; however, barotrauma injury caused by external air-blast is rare [5]. The usual sites affected are the three natural anatomic narrowings: the cricopharyngeus, the crossing of the left main stem bronchus or aortic arch, and the gastroesophageal junction. Symptoms of esophageal perforation vary depending on the cause, location, as well as the time since occurrence. Chest pain and dyspnea are the most common symptoms of esophageal perforation. However, the common presenting symptoms are not specific for esophageal perforation. Diagnosis of an esophageal perforation mainly relies on radiographic evidence. Esophageal contrast study is considered to be the gold standard examination to establish the diagnosis of esophageal lesions and can reveal a contrast leak in most cases of esophageal perforation [6]. The spectrum of severity can vary from minimal leakage of air into the mediastinum to gross disruption and free drainage of esophageal contents into the pleural cavity. Treatment may be conservative or surgical, depending on the cause, site, extent, symptoms, signs, and radiographic findings.

Today it is accepted that the method chosen for the treatment of esophageal perforation plays an important role in the mortality rate. Therefore, while preserving some well-established principles, therapy must not be confined to narrow boundaries. Each case should be evaluated individually [7]. Non-operative management can be easily applied in carefully selected cases. Early recognition and treatment is important. This is possible only if a high index of suspicion is maintained. According to published data, esophageal perforation is most commonly caused by foreign bodies or endoscopic instrumentation. However, in this case erroneous endotracheal intubation and positive air pressure were able to create the perforation, which could be successfully managed conservatively.

Esophageal perforation has been regarded as the most serious injury of the digestive tract. Delayed diagnosis and treatment are associated with prolonged morbidity and high mortality. Foreign bodies are common causes of noniatrogenic esophageal injury [1]. Computed tomography findings including esophageal wall thickening, extraluminal gas, and abscess cavities adjacent to the esophagus are highly suggestive of esophageal perforation [6].

The general consensus is to identify the clinical problem quickly, for timely clearance of the inflamed esophageal focus. The optimal approach to esophageal perforation remains problematical and controversial [8]. A few cases of esophageal perforation have been reported as a result of a sudden release of high pressure air into the esophagus via the mouth [9].

In the case presented in our study, due to the onset of symptoms after intubation, suspicion of tracheal or esophageal injury was raised because of air below the diaphragm and not in the mediastinum, and abdominal esophageal injury was confirmed. Due to the length of the tracheal tube, mechanical trauma to the abdominal esophagus is not considered, so barotrauma due to mis-

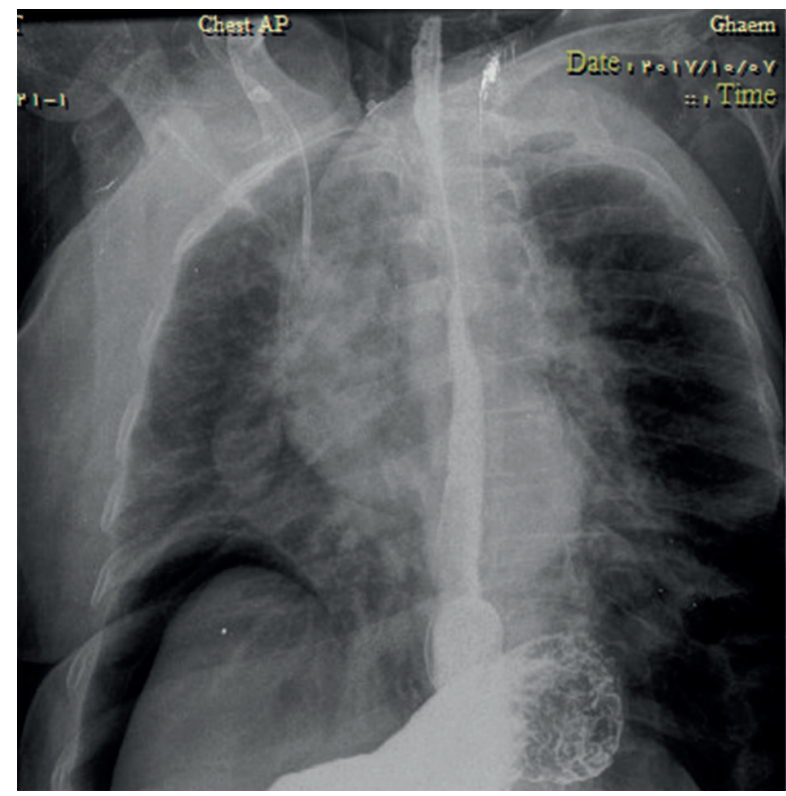

Fig. 2. Contrast study

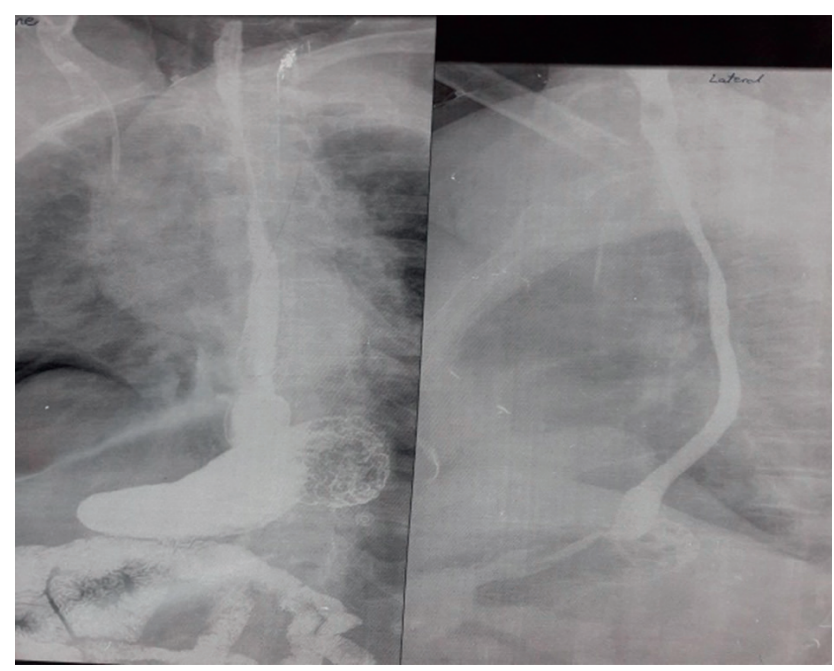

Fig. 3. Contrast study

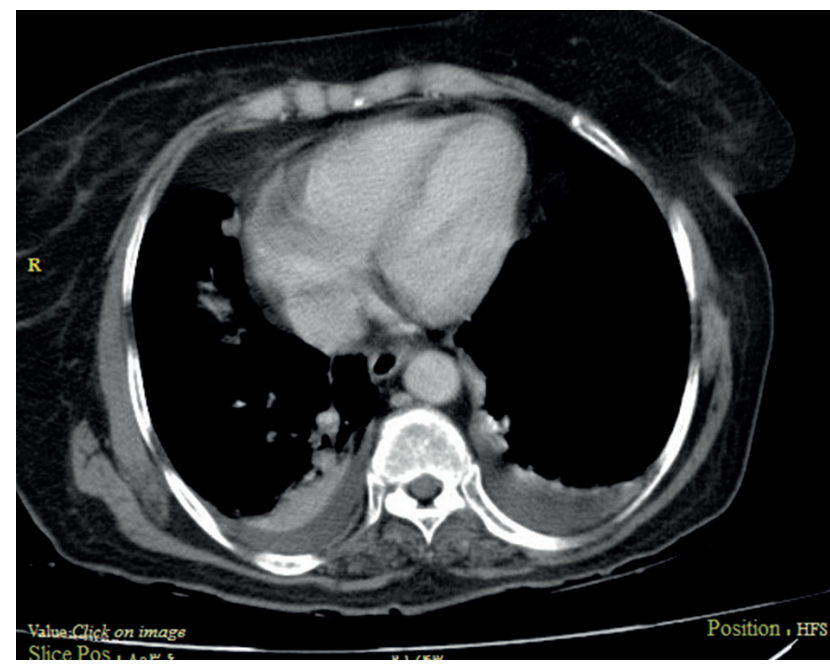

Fig. 4. Chest CT scan 
placement of the endotracheal tube and hyperinflation is the most likely diagnosis in this patient. Because of the good general condition and lack of esophageal contrast leak, a conservative approach was suggested for patient management and we did not perform endoscopy due to the risk of further damage.

\section{Disclosure}

The authors report no conflict of interest.

\section{References}

1. Kanowitz A, Markovchick V. Oesophageal and diaphragmatictrauma. In: Emergency medicine: concepts and clinical practice. Rosen P (ed.). $4^{\text {th }}$ edition. Mosby, St Louis 1998; 546-548.
2. Bresadola V, Terrosu G, Favero A, F Cattin, V Cherchi, Adani GL, Marcellino MG, Bresadola F, De Anna D. Treatment of perforation in the healthy esophagus: analysis of 12 cases. Langenbecks Arch Surg 2008; 393: 135-140.

3. Biancari F, Tauriainen T, Ylikotila T, Kokkonen M, Rintala J, Mäkäräinen-Uhlbäck E, Koivukangas V, Saarnio J. Outcome of stent grafting foresophageal perforations: single-center experience. Surg Endosc 2017; 31: 3696-3702.

4. Søreide J, Viste A. Esophageal perforation: diagnostic work-up and clinical decision making in the first 24 hours. Scand J Trauma Resusc Emerg Med 2011; 19: 66.

5. Zhou Q. An esophageal rupture caused byblast injury. Chin J Misdiagn 2007; 7: 2930.

6. Wu J, Mattox K, Wall M. Esophageal perforations: new perspectives and treatment paradigms. J Trauma 2007; 63: 1173-1184.

7. Nandi P, Ong GB. Foreign body in the oesophagus: a review of 2394 cases. Br J Surg 1978; 65: 5-9.

8. Tsalis K, Vasiliadis K, Tsachalis T, Christoforidis E, Blouhos K, Betsis D. Management of Boerhaave's syndrome: report of three cases. J Gastrointest Liver Dis 2008; 17: 81-85.

9. Lee J, Lim S. Barotraumatic perforation of pharyngoesophagus by the explosion of a bottle into the mouth. Yonsei Med J 2005; 46: 724-728. 